\title{
Salicylic acid and photosynthesis: signalling and effects
}

T. Janda, O. K. Gondor, G. Szalai, M. Pál:

Agricultural Institute, Centre for Agricultural Research, Hungarian Academy of Sciences, H2462 Martonvásár, POB 19, Hungary

R. Yordanova: Institute of Plant Physiology and Genetics, Bulgarian Academy of Sciences, Acad. G. Bonchev Street, Bldg. 21, 1113 Sofia, Bulgaria

Corresponding author: Tibor Janda

Agricultural Institute, Centre for Agricultural Research, Hungarian Academy of Sciences, H2462 Martonvásár, POB 19, Hungary

e-mail: janda.tibor@agrar.mta.hu

Phone: +36 22569509

Fax: +36 22569576

\begin{abstract}
Salicylic acid (SA) is a well-known signalling molecule playing a role in local and systemic acquired resistance against pathogens as well as in acclimation to certain abiotic stressors. As a stress-related signalling compound, it may directly or indirectly affect various physiological processes, including photosynthesis. The effects of exogenously applied SA on plant
\end{abstract}


physiological processes under optimal environmental conditions are controversial. Several studies suggest that SA may have a positive effect on germination or plant growth in various plant species. However, SA may also act as a stress factor, having a negative influence on various physiological processes. Its mode of action depends greatly on several factors, such as the plant species, the environmental conditions (light, temperature, etc.) and the concentration. Exogenous SA may also alleviate the damaging effects of various stress factors, and this protection may also be manifested as higher photosynthetic capacity. Unfavourable environmental conditions have also been shown to increase the endogenous SA level in plants. Recent results strongly suggest that controlled SA levels are important in plants for optimal photosynthetic performance and for acclimation to changing environmental stimuli. The present review discusses the effects of exogenous and endogenous SA on the photosynthetic processes under optimal and stress conditions.

Running title: Salicylic acid and photosynthesis

Keywords: Fluorescence quenching, Net photosynthesis, Oxidative stress, Salicylic acid, Stomatal conductivity, Stress responses

\begin{abstract}
Abbreviations: $\mathrm{CA}$ : cinnamic acid, $C_{\mathrm{i}}$ : Intercellular $\mathrm{CO}_{2}$ concentration, $\mathrm{F}_{\mathrm{m}}$ : maximum chlorophyll-a fluorescence at dark adapted state, , $\mathrm{F}_{\mathrm{v}}$ : variable chlorophyll-a fluorescence at dark adapted state, $g_{\mathrm{s}}$ : stomatal conductivity, ICS: isochorismate synthase, NPQ: nonphotochemical fluorescence quenching, oHCA: ortho-hydroxycinnamic acid, PAL: phenylalanine ammonia lyase, PEPC: phosphoenolpyruvate carboxylase, $\mathrm{P}_{\mathrm{N}}$ : net
\end{abstract}


photosynthetic rate, PS: Photosystem, ROS: reactive oxygen species, SA: salicylic acid; TL: thermoluminescence; $\Phi_{\text {PSII }}$ actual photochemical efficiency of PSII

\section{Introduction}

Phytohormons contribute to all aspects of plant responses towards biotic and abiotic stimuli. They are also indicators of plant stress responses upon variation of light, salinity, temperature, radiation, pollutions (Vogt 2010; Kosova et al. 2012; Majláth et al. 2012). Salicylic acid (SA) is a monohydroxy-benzoic acid, which is well-known signalling molecule playing role in local and systemic acquired resistance against pathogens as well as in acclimation to certain abiotic stressors (Raskin 1992a; Horváth et al. 2007; Szalai et al. 2013; Pál et al. 2013).

SA can be synthesized through phenylalanine pathway. Phenylalanine is converted into cinnamic acid (CA) by phenylalanine ammonia lyase (PAL). PAL is a key regulator of the phenylpropanoid pathway and is induced under a variety of biotic and abiotic stress conditions (Chen et al. 2009). SA can be synthesized from CA via two different routes: it can be either hydroxylated to form ortho-hydroxycinnamic acid (oHCA) followed by oxidation of the side chain or, alternatively, the side chain of cinnamic acid can be initially oxidized to give benzoic acid as an immediate precursor, which is then hydroxylated in the ortho position (Alibert et al. 1972; Hayat et al. 2010). The phenylalanine pathway also serves as a rich source of metabolites in plants, such as flavonoids, coumarins and also lignans (Fraser and Chappel 2011). Different pathways of SA biosynthesis are active in different plant species. Feeding of ${ }^{14} \mathrm{C}$-labeled phenylalanine and cinnamate to young Primula acaulis and American wintergreen leaf segments indicated that SA was formed via oHCA (El-Basyouni 1964). In sunflower, potato and pea, isotope feeding indicated that SA was formed from benzoate, 
which was synthesized by cinnamate chain shortening reactions most likely through a $\beta$ oxidation process analogous to fatty acid $\beta$-oxidation (Klambt 1962).

Recent studies showed that the phenylalanine pathway cannot account for all SA in plant cells, suggesting that there is another main route for SA biosynthesis taking place in the chloroplasts, where SA is synthesized from chorismate via isochorismate in processes catalysed by the isochorismate synthase (ICS) and isochorismate pyruvate lyase enzymes, respectively (Wildermuth et al. 2001; Wildermuth 2006). The role of shikimate pathway in SA synthesis of young pea plants was also demonstrated (Szalai et al. 2011). This shikimic acid pathway is also a link between metabolism of carbohydrates and biosynthesis of aromatic compounds like phenylalanine, tyrosine and tryptophan (Herrman and Weaver 1999).

SA was shown to be tightly linked to further metabolic alterations, affecting redox homeostasis or photosynthetic performance in plants (Mateo et al. 2006). Exogenous applications of SA affect various physiological, biochemical and molecular processes in plants, including antioxidant system (Horváth et al. 2007; Saruhan et al. 2012). It regulates the activities of various antioxidant enzymes such as, peroxidases, superoxide dismutases, catalases etc., which are the major components of induced plant defence against biotic and abiotic stresses (Vicent and Plasencia 2011). Even more, SA has regulatory effect on glutathione homeostasis (Kusumi et al. 2006). SA regulates the components of its own signalling pathway, being involved also in cross-talk with other pathways mediating plant resistance. SA could be utilized for the induction of plant defence system that enables the plant to withstand many biotic and abiotic stresses (War et al. 2011). Photosynthesis is one of the main targets of environmental stressors. The present review is focused on the effects of SA on the photosynthetic processes. 


\section{Effects of exogenous SA on photosynthetic processes under optimal environmental conditions}

SA as a positive plant growth regulator

The effects of exogenously applied SA on plant physiological processes under optimal environmental conditions are controversial. Several studies suggest that SA may positively affect the germination or plant growth in various plant species. For example, enhanced germination and seedling growth were recorded in wheat, when the grains were subjected to pre-sowing seed-soaking treatment in SA (Shakirova 2007). Similarly, aqueous solutions of SA, applied as a spray to the shoots of soybean also significantly increased the growth of shoots and especially roots. However, this treatment had no significant effect on photosynthetic rate (Gutiérrez-Coronado et al. 1998). In contrast to this other authors reported a significant increase in net photosynthesis $\left(\mathrm{P}_{\mathrm{N}}\right)$ in Indian mustard (Brassica juncea L. Czern $\&$ Coss), maize or soybean plants previously sprayed with an optimum concentration $\left(10^{-5} \mathrm{M}\right)$ of SA (Fariduddin et al. 2003; Khan et al. 2003), while higher concentrations of SA had an inhibitory effect. The increase in photosynthetic rates after application of SA was not always accompanied with increased stomatal conductance levels or transpiration rates; however, the intercellular $\mathrm{CO}_{2}$ concentrations of plants sprayed with SA were generally lower than the control plants. This suggests that the increases in photosynthetic rates following spray applications of certain phenolic compounds such as SA could be the result of increased enzyme activity related to $\mathrm{CO}_{2}$ uptake at the chloroplast level, rather than simple increases in stomatal opening (Khan et al. 2003). However, the exact mechanism of the photosynthesis enhancement is still unclear. 
Both soaking of seeds or foliar application of SA can also be fruitful in increasing the pigment contents, as it was shown in wheat (Hayat et al. 2005) or in rapeseed (Brassica napus L.) (Ghai et al. 2002). However, the positive effect of SA on photosynthetic activity is not always due to an increased chlorophyll level. In cowpea (Vigna unguiculata) plants SA treatment increased or decreased chlorophyll content, depending on the genotype (Chandra and Bhatt 1998) or the applied concentration, as $0.001-10 \mu \mathrm{M}$ SA increased, while $1 \mathrm{mM}$ SA decreased both chlorophyll and carotenoid contents in the cotyledons of sunflower plants (Cag et al. 2009).

SA as a stress factor

Several studies also show that SA may serve as a stressor as well, which among others, negatively affects the photosynthetic processes, especially above a threshold concentration. The effective concentration may highly depend on the plant species, the way of the application, the duration of the treatment, and the environmental conditions. For example, addition of $0.5 \mathrm{mM} \mathrm{SA}$ to the hydroponic solution of young maize plants - the same concentration as that provided protection against low temperature-induced damage in young maize (Janda et al. 1999) or could alleviate the damaging effect of paraquate in barley (Ananieva et al. 2002) - decreased the net photosynthesis under both light-limited and lightsaturated conditions together with a decrease in the stomatal conductance $\left(\mathrm{g}_{\mathrm{s}}\right)$ and transpiration rate. Intercellular $\mathrm{CO}_{2}$ concentration $\left(\mathrm{C}_{\mathrm{i}}\right)$ was higher in the dark and lower in the light in the SA-treated plants than in the untreated control maize plants (Janda et al. 1999), respectively. Similarly, while short-term treatment of barley seedlings with SA (for minutes up to 2 hours) did not affect the rate of photosynthesis, leaf or root growth; the chlorophyll and protein contents and the maximal rate of photosynthesis were also reduced by a long-term 
treatment with SA together with an increase in both the $\mathrm{CO}_{2}$ compensation point and stomatal resistance (Pancheva et al. 1996). Increasing SA concentrations also resulted in a significant decrease in the maximum and effective quantum yields of PSII photochemistry $\left(\mathrm{F}_{\mathrm{v}} / \mathrm{F}_{\mathrm{m}}\right.$ and $\Phi_{\text {PSII }}$, respectively) and in the photochemical quenching parameter in guard cells of tomato plants. In the presence of low SA concentration $\left(10^{-7}\right.$ or $\left.10^{-4} \mathrm{M}\right)$, the chloroplasts of guard cells sustained a higher electron transport rate than in the presence of $10^{-3} \mathrm{M}$, suggesting that the SA-induced inhibition of guard cell photosynthesis may affect stomatal closure at high SA concentrations (Poór and Tari 2012). Application of SA to Arabidopsis leaves also rapidly induced stomatal closure and photoinhibition that ended up in photodamage (Mateo et al. 2004). It must also be mentioned that not only SA, but certain related compounds, such as acetylsalicylate (aspirin), or a possible precursor benzoic acid showed similar effects. These compounds, besides affecting the gas exchange rates, may also influence the processes related to the photosynthetic electron transport via enhancing the non-photochemical fluorescence quenching (NPQ) mechanisms (Janda et al. 2000).

Transients of the development of NPQ during continuous illumination were also modified in the SA-infiltrated tobacco leaves, indicating that SA influenced the build-up of the transmembrane pH gradient (Janda et al. 2012). The slower development of NPQ after exposing the leaves to light in SA-infiltrated tobacco leaves may also be due to a slower rate of zeaxanthin formation (Bilger and Björkman 1991). Light response curves of NPQ showed that SA treated leaves had limited capacities of regulated energy dissipation, especially at higher light intensities. The highly reduced rate of electron transport occurring under high light conditions may also explain the reduced NPQ in plants treated with SA at high concentration (Janda et al. 2012).

In barley plants the ribulose-1,5-bisphosphate carboxylase activity decreased while the activity of phosphoenolpyruvate carboxylase (PEPC, EC 4.1.1.31) increased with increasing 
SA concentrations (Pancheva et al. 1996). The observed inhibition of photosynthesis and the activity of Rubisco by SA are mainly caused by a decrease in the Rubisco content (Pancheva et al. 1998). However, short-term treatment of barley seedlings with SA also decreased the levels of chlorophyll, $\mathrm{CO}_{2}$ assimilation and transpiration rates without changes in the Rubisco activity (Ananieva et al. 2002). These results suggested that SA may cause a decrease in photosynthetic activity under normal growth conditions; however, the influences on the Rubisco activity seem to be secondary, long-term effects. Furthermore, in a recent proteomic study with maize plants, the SA responsive protein, Rubisco large subunit, which was represented by two protein spots interestingly showed opposite expression patterns at protein level: one was up-regulated while the other was down-regulated. One hypothesis concerning this phenomenon is that the same protein in maize leaves may have different isoforms and have different roles under phytohormone stress (Wu et al. 2013). Pyruvate orthophosphate dikinase, which plays a controlling role in the PEP-regeneration phase of the C4 photosynthetic pathway, was also down-regulated by SA treatment in maize leaves (Wu et al. 2013).

While growing of wheat plants in solution containing a wide range of SA concentrations $(0.05-1 \mathrm{mM})$ stimulated the electron flow associated with Photosystem II, the Photosystem I-associated electron transport activity was only stimulated at low concentrations of SA, and at higher concentrations it was drastically attenuated (Sahu et al. 2002). Thylakoids isolated from the leaves of wheat seedlings grown with high concentrations showed a substantial reduction in uncoupler $\left(\mathrm{NH}_{4} \mathrm{Cl}\right)$-mediated stimulation in electron flow. In addition, they failed to support ADP-dependent stimulation of electron transport activity and induced a significant reduction in ATPase activity. Incubation of isolated thylakoids with SA, however, had no effect on thylakoid photofunction, indicating no direct effect of SA on photoelectron transport activity. Furthermore, high concentrations of SA specifically reduce 
the thylakoid cytochrome $\mathrm{f}_{554}$ level. The results suggest that $\mathrm{SA}$, depending on its concentration, imparts differential effects on the photofunction of thylakoids. A low concentration of SA may favour photosynthetic activity while the high concentration induces its drastic attenuation partly due to the decline in cytochrome $f_{554}$ (Sahu et al. 2002).

When 7-day old barley seedlings were supplied with SA through the transpiration stream for $24 \mathrm{~h}$ no marked changes in photosynthetic reactions were observed (Maslenkova et al. 2009). However, exposure of barley plants to SA imposed through the root medium for a period of 7 days have a marked effect on the charge recombination of both intact leaves and isolated chloroplast, characterised by thermoluminescence (TL) measurements. These results suggested that SA action was on thylakoid membrane level. SA treatment decreased the number of PSII centres and disturbed the redox cycling of the rest operative water-oxidising centres. Reduction of Hill-reaction activity and oxygen flash yields is in accordance with the changes in membrane permeability and malondialdehyde content indicating that long-term SA treatment leads to the development of oxidative stress symptoms. It has also been shown that prolonged treatment with SA resulted in a great number of quantitative alterations in polypeptide composition (Metodiev et al. 2002). The changes in polypeptides belonging to PSII and especially the extrinsic polypeptides of water-oxidizing complex may be important. Thylakoid membranes isolated from SA-treated plants showed strong depletion of $33 \mathrm{kDa}$ extrinsic polypeptide. This protein is important for the functional integrity of the manganese cluster, which catalyses photosynthetic water-splitting; and may also bind GTP pointing to additional functions e.g., participation in signal transduction associated with the thylakoid membrane, possibly connected to the GTP-dependent turn-over of the D1 protein (Spetea et al. 2004). The decrease in its quantity may affect the conformation of PSII reaction centre and the redox properties of some other redox components of electron transport chain. The observed alterations in chloroplast membrane composition as well as the changes in 
membrane granal structure during prolonged SA application to the root medium of barley seedlings (Uzunova and Popova 2000) may be a prerequisite for the inhibition of PSII functional activity. SA-induced changes in PSII structure and functions suggested a picture, which is starting to outline that a mechanism other than stomata function can also be involved in the inhibition of photosynthesis (Maslenkova et al. 2009).

Infiltration of $\mathrm{SA}$ in tobacco leaves also reduced the $\mathrm{CO}_{2}$ incorporation and stomatal conductivity. In these plants PSII electron transport was more sensitive to SA than PSI. Direct probing of PSII charge separation and stabilization measured with TL, however, showed that these events were much less affected in isolated thylakoid membranes than in intact leaves, supporting the idea that the effect of SA on PSII is indirect (Janda et al. 2012). In addition to changes in energy partitioning, over-reduction of PSII may also lead to the formation of reactive oxygen species (ROS). Detecting elevated amounts of $\mathrm{H}_{2} \mathrm{O}_{2}$ in SA treated leaves supports this possibility (Janda et al. 2012). Accumulation of $\mathrm{H}_{2} \mathrm{O}_{2}$ in the cells also suggests that SA also has a secondary, indirect effect, which is light independent (Fig. 1).

So exogenous SA treatment may either increase or decrease the photosynthetic activity of plants. This may also depend on the species, although the fact that similar effects can also be observed in various genetically different plant types $\left(\mathrm{C}_{3}\right.$ or $\mathrm{C}_{4}$ types of photosynthesis; monocots or dicots; etc.), suggests that other factors, such as concentration, duration of the treatment, way of the application (spraying, adding to hydroponic or soaking of seeds), or environmental condition (temperature, light) may have more important influence than the species specificity itself.

\section{Effects of exogenous SA on photosynthetic processes under stress conditions}


Several stressors may directly or indirectly severely affect the photosynthetic processes (Majláth et al. 2012; Ashraf and Harris 2013). It has been well documented that exogenous SA may alleviate the damaging effects of various stress factors, and this protection can also be manifested in higher photosynthetic capacity (Horváth et al. 2007, Hayat et al. 2010, Radwan and Soltan 2012, Sasheva et al. 2013, Tirani et al. 2013). For example, pre-soaking of seeds in $0.5 \mathrm{mM}$ SA solution for $6 \mathrm{~h}$ before sowing substantially decreased harmful effects of cadmium on $\mathrm{CO}_{2}$ fixation in maize (Krantev et al. 2008) or pea (Popova et al. 2009). The activities of carboxylating enzymes PEPC and especially Rubisco were also negatively affected by Cd treatment. However, pre-treatment of maize plants with SA before exposure to Cd alleviated the inhibitory effect of Cd on Rubisco, and led to a nearly 2-fold increase in PEPC activity compared with untreated plants (Krantev et al. 2008).

The illumination of unfrozen dark adapted leaves from pea plants with one short saturating flash induces a main TL peak at $35{ }^{\circ} \mathrm{C}$, the B-band, which is the result of charge recombination between the S2 state of the water splitting system and the secondary quinone acceptor $\mathrm{Q}_{\mathrm{B}}$, together with a hardly distinguishable shoulder at temperature about $40{ }^{\circ} \mathrm{C}$. The latter is referred as AG (afterglow)-band, and is due to a heat-induced electron transfer from stroma reductants to PSII centres initially in the non-recombining state $S 2 / 3 \mathrm{Q}_{\mathrm{B}}$, which is enabled to emit AG luminescence as soon as $\mathrm{Q}_{\mathrm{B}}$ is reduced by back-electron transfer (Ducruet 2003). A damping of period-four oscillation of the B-band intensity, according to exciting flash number was also observed at high concentration of Cd together with a decrease in the AG/B ratio. This tendency was much better expressed in the case of TL induction by short far-red illumination of dark adapted pea leaves. This kind of illumination excites mainly PSI but a part of the energy can be absorbed in PSII antenna leading to charge separation and the induction of TL B-band. Short term application of SA to the pea seeds did not exert changes in the investigated TL parameters. However, pre-treatment with SA before the imposition of 
high concentration of heavy metal $\mathrm{Cd}$ had a stabilizing effect on photochemical reactions, as indicated by some restoration of $\mathrm{AG} / \mathrm{B}$ ratio and $\mathrm{B}-$ band oscillation pattern (Popova et al. 2009).

The photosynthetic thylakoid has the highest level of lipid unsaturation of any membrane. Cd caused a shift in fatty acids composition, resulting in a lower degree of their unsaturation and an increase in saturated fatty acids in sunflower leaves, whereas SA improved them. SA particularly increased the percentage of linolenic acid and lowered that of palmitic acid by the same proportion. These results suggest that SA could be used as a potential growth regulator and a stabilizer of protection of cadmium-induced oxidative stress to improve plant resistance to Cd stress (Moradkhani et al. 2012).

SA also counteracted salt stress-induced growth inhibition (Singh and Gautam 2013) and enhanced the net photosynthetic rate $\left(\mathrm{P}_{\mathrm{N}}\right)$ in wheat (Arfan et al. 2007) and in tomato plants (Gémes et al. 2008, Poór et al. 2011). Foliar spraying with SA caused increase in $\mathrm{g}_{\mathrm{s}}$, but it did not change the sub-stomatal $\mathrm{CO}_{2}$ during salt stress in sunflower (Noreen and Ashraf 2008). In cucumber foliar spraying of $0.5-2.5 \mathrm{mM}$ SA before low temperature and light intensity treatment reversed the stress-induced decrease of the leaf $\mathrm{P}_{\mathrm{N}}, \mathrm{g}_{\mathrm{s}}$, transpiration rate, $\Phi_{\text {PSII }}$, and $F_{\mathrm{v}} / F_{\mathrm{m}}$, and increase of the $\mathrm{C}_{\mathrm{i}}$ (Liu et al. 2009). It is suggested that the stomatal limitations were not the controlling factors for photosynthesis; and SA may affect certain metabolic factors in carbon uptake or fixation including Rubisco enzyme concentration and activity, and/or photosynthetic carbon reduction cycle. Similar conclusion was found during salt stress, as the improvement in growth and grain yield due to SA application was associated with improved photosynthetic capacity, which was not due to stomatal limitations, but was associated with metabolic factors, other than photosynthetic pigments and leaf carotenoids (Arfan et al. 2007). 
It was also reported that exogenous SA could protect the photosynthetic apparatus against strong light-induced photodamage in Satsuma mandarin leaves. This protective effect was related to electron transport rate and quantum yield of PSII, and relative contents of D1 protein and Deg1 protease induced by exogenous SA under combined high temperature and strong light conditions (Qiu et al. 2011). SA pre-treatment in wheat could not only increase the protein kinase activity, retard the degradation of D1 protein during heat and high light stress, but also accelerated the recovery of D1 protein level when the stress was removed. Correspondingly, the maximum and the actual photochemical efficiency of PSII, electron transfer rate and $\mathrm{P}_{\mathrm{N}}$ in SA-treated leaves were higher than that in leaves of control under both stress and non-stress conditions. These results suggest that SA pre-treatment could significantly alleviate damages of heat and high light stress on PSII in wheat leaves, and accelerate restoration of photosynthetic function (Zhao et al. 2011).

SA did not influence $\mathrm{P}_{\mathrm{N}}$ of leaves of grapevine plants under normal conditions, while SA could alleviate declines in $\mathrm{P}_{\mathrm{N}}$ and Rubisco activition state.SA and did not alter negative changes in PSII parameters (donor side, acceptor side and reaction centre $\mathrm{Q}_{\mathrm{A}}$ ) under heat stress. Following heat treatment, the recovery of $\mathrm{P}_{\mathrm{N}}$ in SA-treated leaves was accelerated compared to the control, and donor and acceptor parameters of PS II in SA-treated leaves recovered to normal levels more rapidly than in the controls. Before heat stress, SA did not affect level of HSP21, but the HSP21 immune signal increased in both SA-treated and control leaves during heat stress. During the recovery, HSP21 levels remained high through the end of the experiment in the SA-treated leaves, but decreased in controls. Based on these results it was concluded that SA pre-treatment alleviated the heat stress induced decrease in $\mathrm{P}_{\mathrm{N}}$ mainly through maintaining higher Rubisco activition state, and it accelerated the recovery of $\mathrm{P}_{\mathrm{N}}$ mainly through effects on PSII function. These effects of SA may be related in part to enhanced levels of HSP21 (Wang et al. 2010). 


\section{Endogenous SA and photosynthesis}

Level of SA varies in the range of several orders of magnitude in the different plant species. Under optimal environmental conditions usually very low concentrations (in the range of a few 10-100 ng/g FW) can be detected from the leaves of Arabidopsis, tobacco, maize or wheat plant (Meuwly and Métraux 1993, Mateo et al. 2006, Janda et al. 2007, Szalai and Janda 2009). Certain environmental stimuli, such as pathogen infection, heavy metal contamination, or the use of direct oxidative agent may dramatically, in some cases even in 10-50-fold increase it up to the range of $\mu \mathrm{g} / \mathrm{g}$ FW (Raskin 1992b, Enyedi 1999; Pál et al. 2005). However, in some species, such as rice, the basic acid level in the leaves is usually as high as 30-40 $\mu \mathrm{g} / \mathrm{g}$ FW (Silverman et al. 1995, Pál et al. 2014).

Plants with reduced SA levels

Arabidopsis mutant sid2 defective in SA synthesis or NahG plants expressing a bacterial salicylate hydroxylase can be characterised with decreased levels of SA, they usually display impaired pathogen defence and slightly impaired PSII operating efficiency and enhanced thermal energy dissipation under low light conditions without impairment of growth or reduced levels of starch. However, these mutants seemed to be unable to increase photosynthetic electron transport efficiency or glutathione levels to the same extent as wild type plants during exposure to high light suggesting that appropriate levels of SA and/or $\mathrm{H}_{2} \mathrm{O}_{2}$ are required proper light acclimation responses. To compensate their lower ability in light acclimation, these plants need other acclimation processes, for example elevated level of anthocyanin level. These results strongly support the hypothesis that controlled SA levels are 
important for optimal photosynthetic performance and growth under different light conditions (Mateo et al. 2006). SA-degrading transgenic $N a h G$ plants targeted either to the cytoplasm or chloroplasts displayed normal state transition, therefore, the role of SA in state transition could be excluded (Gawronski et al. 2013).

Plants have evolved several mechanisms to get rid of this excess energy in photosynthetic membranes, some of which involve isoprenoid compounds. $\alpha$-Tocopherol and carotenoids represent a conserved mechanism of photoprotection, while other isoprenoids, such as monoterpenes, represent an additional or alternative photoprotection mechanism (Penuelas and Munné-Bosch 2005). $\alpha$-Tocopherol and carotenoids display antioxidant activity and therefore contribute to maintenance of thylakoid membrane structure and function under stress. In another experiment while no substantial differences in RWC were observed between wild type and SA-deficient NahG transgenic lines of Arabidopsis plants, SA deficiency suppressed the water stress-induced loss of chlorophylls and carotenoids observed in the wild type. In addition, accumulations of monoterpenes and $\alpha$-tocopherol were also suppressed in $N a h G$ plants both under irrigated and water stress conditions, although the effects were more apparent under stress when as this was more severe. Results suggest that SA affects isoprenoid accumulation in leaves especially under water stress conditions. It is assumes that SA may also be involved in accelerating water-stress induced chlorophyll loss, which may be probably linked with an accelerated senescence under stress (Munné-Bosch et al. 2007).

Plants with elevated SA levels

Arabidopsis mutants with high SA content, such as cpr1-1, cpr5-1, cpr6-1 or dnd1-1 were usually characterised by dwarf phenotype (Mateo et al. 2006). However, this dwarfism was 
less pronounced when these plants were grown in high light, suggesting that the inhibitory effect of SA on growth was partly overcome at higher light intensities. On the other hand, mutants with low foliar SA content were impaired in acclimation to transient exposure to high light and thus predisposed to oxidative stress. In rice plants, which have two orders of magnitude higher levels of SA than the majority of plant species and appear to be insensitive to exogenous SA treatment, SA also plays an important role to modulate redox balance and protect plants from oxidative stress (Yang et al. 2004). These observations implied an essential role of SA in the light acclimation processes (Mateo et al. 2006).

The increased or reduced levels of SA may impair the photosynthetic processes in a different way (Mateo et al. 2006). The $d n d 1-1$ (defence no death) mutation in Arabidopsis plants affects a cyclic nucleotide gated cation channel (AtCNGC2) and induces constitutive SA-dependent pathogen resistance in the absence of hypersensitive cell death (Yu et al. 1998, Clough et al. 2000). Cpr5 is a membrane protein of unknown function and mutations in Cpr5 have pleiotropic effects on the regulation of cell death, cell elongation, and trichome development (Kirik et al. 2001, Yoshida et al. 2002). These mutants could be characterised with constitutively high levels of SA, and showed reduced stomatal conductance, higher dark respiration and lower maximum $\mathrm{CO}_{2}$ assimilation rates, decreased maximum efficiency and quantum yield of PSII, and increased NPQ representing the thermal dissipation of absorbed light energy under low light conditions. However, accumulation of photoassimilates as starch strongly decreased in $d n d 1-1$, but not $c p r 5-1$, possibly indicating changes in assimilate partitioning (Mateo et al. 2006). Although mutants with high foliar SA content had lower maximum and operating efficiency of PSII than the wild-type, they were able to increase glutathione content and to improve the operating efficiency of PSII during acclimatory responses to high light stress. The inhibitory effects of foliar SA, glutathione, and $\mathrm{H}_{2} \mathrm{O}_{2}$ 
accumulation observed under low light conditions seem to be less pronounced at high light when the metabolism is adjusted to higher levels of these compounds.

Photosynthetic electron transport characteristics, $\mathrm{H}_{2} \mathrm{O}_{2}$, glutathione biosynthesis and changes in leaf water status have been implicated in the signalling pathway regulating the expression of Apx2 encoding a cytosolic ascorbate peroxidase gene. Besides its antioxidant role ascorbate may also play a role in the regulation of photosynthetic electron transport processes (Tóth et al. 2013). A lower threshold for Apx2 induction was consistently observed in mutants with elevated SA levels (Mateo et al. 2006).

In contrast to Arabidopsis, where SA overproduction leads to dwarfism, transgenic Populus tremula $\times$ alba expressing a bacterial SA synthase hyperaccumulated SA and SA conjugates without negative growth consequences (Xue et al. 2013). In the absence of stress, endogenously elevated SA elicited widespread metabolic and transcriptional changes that resembled those of wild-type plants exposed to oxidative stress-promoting heat treatments. Potential signalling and oxidative stress markers azelaic and gluconic acids as well as antioxidant chlorogenic acids were strongly co-regulated with SA, while soluble sugars and other phenylpropanoids were inversely correlated. Photosynthetic responses to heat were attenuated in SA-overproducing plants. Network analysis identified potential drivers of SAmediated transcriptome rewiring, including receptor-like kinases and WRKY transcription factors. Orthologs of Arabidopsis SA signalling components NON-EXPRESSOR OF PATHOGENESIS-RELATED GENES1 (NPR1) and thioredoxins were not represented. However, all members of the expanded Populus nucleoredoxin-1 family exhibited increased expression and increased network connectivity in SA-overproducing Populus, suggesting a previously unknown role in SA-mediated redox regulation. The SA response in Populus involved a reprogramming of carbon uptake and partitioning during stress that is compatible 
with constitutive chemical defence and sustained growth, contrasting with the SA response in Arabidopsis, which is transient and compromises growth if sustained.

Stress-induced SA levels

In addition to the application of exogenous SA being reported to provide protection against several types of stressors, unfavourable environmental conditions have also been shown to increase the endogenous SA level in plants (Horváth et al. 2007, Szalai and Janda 2009, Pál et al. 2013). It has long been suggested that different stressors, such as UV light, ozone fumigation or virus infection can activate a common signal transduction pathway that leads to SA accumulation and increased stress resistance (Yalpani et al. 1994). SA accumulation in Nicotiana benthamiana depended on ICS activity: total SA levels increased more in wild-type plants than in plants with silenced ICS expression after UV irradiation treatment (Catinot et al. 2008).

Similarly to other stressors, low temperature could also induce endogenous SA accumulation in cucumber leaves, and this accumulation could be prevented by spraying with an inhibitor of SA biosynthesis, paclobutrazol. Low temperature resulted in a reduction in maximum and effective photochemical efficiency of PSII, and electron transport rate. Spraying with paclobutrazol enhanced the reduction in PSII efficiency. Low temperature stress led to a decreased allocation of light absorbed by PSII antenna to the photochemical reaction and an increased allocation of excessive energy, and paclobutrazol-treatment caused a greater allocation of light to dissipation as excessive energy. The expression of genes encoding the Rubisco small subunit and carbonic anhydrase was down-regulated by low temperature stress, and the reduction was greater in paclobutrazol-treated seedlings. These results suggested that low temperature-induced SA accumulation was required for 
maintenance of photosynthetic efficiency and carbon assimilation capacity, and thereby protected cucumber seedlings against low temperature-induced damages (Li et al. 2013).

Furthermore, exogenous SA may also enhance the plant's own de novo SA synthesis, as it was illustrated by the changes in free and bound SA levels in pea plants growing from seeds pre-treated with SA before sowing (Szalai et al. 2011). Pre-soaking the seeds in SA also increased the activities of some antioxidant enzymes, namely ascorbate peroxidase and guaiacol peroxidase and the level of $o \mathrm{HCA}$, which may also affect the tolerance to environmental stressors (Fig. 2).

\section{Conclusion}

As a stress-related signalling compound, SA may directly or indirectly affect various physiological processes, including photosynthesis. Its mode of action depends greatly on several factors, such as the plant species, the environmental conditions (light, temperature, etc.) and the concentration. When it is applied exogenously, it may provide protection against various types of stressors; however, above a threshold concentration it may also cause damage. Although several phenolic compounds have been shown to have a direct effect on the photosynthetic electron transport chain, the majority of results suggest that the effect of SA on the photosynthetic machinery is indirect, originating from its influence on stomatal conductivity. ROS also play a decisive role in both the upstream and downstream processes of SA signalling. Recent results strongly suggest that controlled SA levels are important in plants for optimal photosynthetic performance and for acclimation to changing environmental stimuli. 
Author contribution T. Janda collated all the input from the co-authors and drafted the entire manuscript. G. Szalai and R. Yordanova prepared Fig. 1. O. K. Gondor mainly wrote parts related to SA biosynthesis and the draft of Introduction. M. Pál mainly contributed to the stress-related subchapters. All the authors read and approved the manuscript in its final form.

Acknowledgements This work was supported by Hungarian National Research Fund (OTKA PD 83840; K 108838/108834). Magda Pál is a grantee of János Bolyai scholarship.

\section{References}

Alibert G, Boudet, A, Ranjeva, R (1972) Studies on the enzymes catalysts of biosynthesis of phenolic acids in Quercus pedunculata. III. Sequential formation of cinnamic, pcoumaric and caffeic acids from phenylalanine by isolated cell organelles. Physiol Plant 27:240-243

Ananieva EA, Alexieva VS, Popova LP (2002) Treatment with salicylic acid decreases the effects of paraquat on photosynthesis. J Plant Physiol 159:685-693

Arfan M, Athar HR, Ashraf M (2007) Does exogenous application of salicylic acid through the rooting medium modulate growth and photosynthetic capacity in two differently adapted spring wheat cultivars under salt stress? J Plant Physiol 164:685-694

Ashraf M, Harris PJC (2013) Photosynthesis under stressful environments: An overview. Photosynthetica 51:163-190

Bilger W, Bjorkman O (1991) Temperature dependence of violaxanthin deepoxidation and non-photochemical fluorescence quenching in intact leaves of Gossypium kirsutum L. and Malva parviflora L. Planta 184:226-234 
Çag S, Cevahir-Öz, G, Sarsag M, Gören-Saglam N (2009) Effect of salicylic acid on pigment, protein content and peroxidase activity in excised sunflower cotyledons. Pak J Bot 41:2297-2303

Catinot J, Buchala A, Abou-Mansour E, Metraux JP (2008) Salicylic acid production in response to biotic and abiotic stress depends on isochorismate in Nicotiana benthamiana. FEBS Lett 582:473-478

Chandra A, Bhatt RK (1998) Biochemical physiological response to salicylic acid in relation to the systemic acquired resistance. Photosynthetica 35:255-258

Chen Z, Zheng Z, Huang J, Lai Z, Fan B (2009) Biosynthesis of salicylic acid in plants. Plant Sign Behav 4:493-496

Clough SJ, Fengler KA, Yu IC, Lippok B, Smith Jr RK, Bent AF (2000) The Arabidopsis dndl 'defense, no death' gene encodes a mutated cyclic nucleotide-gated ion channel. Proc Nat Acad Sci USA 97:9323-9328

Ducruet JM (2003) Chlorophyll thermoluminescence of leaf discs: simple instruments and progress in signal interpretation open the way to new ecophysiological indicators. J Exp Bot 54:2419-2430

El-Basyouni SZ, Chen D, Ibrahim RK, Neish AC, Towers GHN (1964) The biosynthesis of hydroxybenzoic acids in higher plants. Phytochemistry 3:485-492

Enyedi AJ (1999) Induction of salicylic acid biosynthesis and systemic acquired resistance using the active oxygen species generator rose bengal. J Plant Physiol 154:106-112

Fariduddin Q, Hayat S, Ahmad A (2003) Salicylic acid influences net photosynthetic rate, carboxylation efficiency, nitrate reductase activity, and seed yield in Brassica juncea. Photosynthetica 41:281-284

Fraser CM, Chappel C (2011) The phenylpropanoid pathway in Arabidopsis. The Arabidopsis Book 9:e0152 
Gawroński P, Górecka M, Bederska M, Rusaczonek A, Ślesak I, Kruk J, Karpiński S (2013) Isochorismate synthase 1 is required for thylakoid organization, optimal plastoquinone redox status, and state transitions in Arabidopsis thaliana. J Exp Bot 64:3669-3679

Gémes K, Poór P, Sulyok Z, Szepesi Á, Szabó M, Tari I (2008) Role of salicylic acid pretreatment in the photosynthetic performance of tomato plants (Lycopersicon esculentum Mill. L. cvar. Rio Fuego) under salt stress. Acta Biol Szegediensis 52:161162

Ghai N, Setia RC, Setia N (2002) Effects of paclobutrazol and salicylic acid on chlorophyll content, hill activity and yield components in Brassica napus L. (cv. GSL-1). Phytomorphology 52:83-87

Gutiérrez-Coronado MA, Trejo-López C, Larqué-Saavedra A (1998) Effect of salicylic acid on the growth of roots and shoots in soybean. Plant Physiol Biochem 36:563-565

Hayat Q, Hayat S, Irfan M, Ahmad A (2010) Effect of exogenous salicylic acid under changing environment: A review. Environ Exp Bot 68:14-25

Hayat S, Fariduddin Q, Ali B, Ahmad A (2005) Effect of salicylic acid on growth and enzyme activities of wheat seedlings. Acta Agron Hung 53:433-437

Herrman KM, Weaver LM (1999) The shikimate pathway. Annu Rev Plant Physiol Plant Mol Biol 50:473-503

Horváth E, Szalai G, Janda T (2007) Induction of abiotic stress tolerance by salicylic acid signaling. J Plant Growth Regul 26:290-300 2007

Janda T, Szalai G, Tari I, Páldi E (1999) Hydroponic treatment with salicylic acid decreases the effects of chilling injury in maize (Zea mays L.) plants. Planta 208:175-180

Janda T, Szalai G, Antunovics Z, Horváth E, Páldi E (2000) Effect of benzoic acid and aspirin on chilling tolerance and photosynthesis in young maize plants. Maydica 45:29-33 
Janda T, Szalai G, Leskó K, Yordanova R, Apostol S, Popova LP (2007) Factors contributing to enhanced freezing tolerance in wheat during frost hardening in the light. Phytochemistry 68:1674-1682

Janda K, Hideg É, Szalai G, Kovács L, Janda T (2012) Salicylic acid may indirectly influence the photosynthetic electron transport. J Plant Physiol 169:971-978

Khan W, Prithiviraj B, Smith DL (2003) Photosynthetic responses of corn and soybean to foliar application of salicylates. J Plant Physiol 160:485-492

Klambt HD (1962) Conversion in plants of benzoic acid to salicylic acid and its b-Dglucoside. Nature 196:491

Kosova K, Prasil IT, Vitamvas P, Dobrev P, Motyka V, Flokova K, Novak O, Turecková V, Rolcik J, Pesek B, Travnickova A, Gaudinova A, Galiba G, Janda T, Vlasakova, E, Prasilova P, Vankova R (2012) Complex phytohormone responses during the cold acclimation of two wheat cultivars differing in cold tolerance, winter Samanta and spring Sandra. J Plant Physiol 169:567-576

Krantev A, Yordanova R, Janda T, Szalai G, Popova L (2008) Treatment with salicylic acid decreases the effect of cadmium on photosynthesis in maize plants. J Plant Physiol 165:920-931.

Krik V, Bouyer D, Schöbinger U, Bechtold N, Herzog M, Bonneville JM, Hülskamp M (2001) CPR5 is involved in cell proliferation and cell death control and encodes a novel transmembrane protein. Curr Biol 11:1891-1895

Kusumi K, Yaeno T, Kojo K, Hirayama M, Hirokawa D, Yara A, Iba K (2006) The role of salicylic acid in the glutathione-mediated protection against photooxidative stress in rice. Physiol Plant 128:651-661 
Li L, Dong CJ, Shang QM (2013) Role of endogenous salicylic acid in responding of cucumber leaf photosynthetic systems to low temperature stress. Acta Horticult Sinica 40:487-497

Liu W, Ai XZ, Liang WJ, Wang HT, Liu SX, Zheng N (2009) Effects of salicylic acid on the leaf photosynthesis and antioxidant enzyme activities of cucumber seedlings under low temperature and light intensity. Chinese J Appl Ecol 20:441-445

Majláth I, Szalai G, Soós V, Sebestyén E, Balázs E, Vanková R, Dobrev PI, Tandori J, Janda $\mathrm{T}$ (2012) Effect of light on the gene expression and hormonal status of winter and spring wheat plants during cold hardening. Physiol Plant 145:296-314

Maslenkova L, Peeva V, Stojnova Z, Popova L (2009) Salicylic acid-induced changes in photosystem II reactions in barley plants. Biotechnol Biotechnol eq 23/2009/se special edition/on-line.

Mateo A, Funck D, Mühlenbock P, Kular B, Mullineaux PM, Karpinski S (2006) Controlled levels of salicylic acid are required for optimal photosynthesis and redox homeostasis. $\mathrm{J}$ Exp Bot 57:1795-1807

Mateo A, Mühlenbock P, Rusterucci C, Chang CC, Miszalski Z, Karpinska B, Parker JE, Mullineaux PM, Karpinski S (2004) Lesion Simulating Disease 1 is required for acclimation to conditions that promote excess excitation energy. Plant Physiol $136: 2818-2830$

Metodiev MV, Kicheva MI, Stoinova ZG, Popova LP (2002) Two-dimensional electrophoretic analysis of salicylic acid-induced changes in polypeptide pattern of barley leaves. Biol Plant 45:585-588

Meuwly P, Métraux JP (1993) Ortho-anisic acid as internal standard for the simultaneous quantitation of salicylic acid and its putative biosynthetic precursors in cucumber leaves. Anal Biochem 214:500-505 
Moradkhani S, Khavari Nejad RA, Dilmaghani K, Chaparzadeh N (2012) Effect of salicylic acid treatment on cadmium toxicity and leaf lipid composition in sunflower. J Stress Physiol Biochem 8:78-89

Munné-Bosch S, Penuelas J, Llusia J (2007) A deficiency in salicylic acid alters isoprenoid accumulation in water-stressed NahG transgenic Arabidopsis plants. Plant Sci 172 756762

Noreen S, Ashraf M (2008) Alleviation of adverse effects of salt stress on sunflower (Helianthus annuus L.) by exogenous application of salicylic acid: growth and photosynthesis. Pak J Bot 40:1657-1663

Pál M, Horváth E, Janda T, Páldi E, Szalai G (2005) Cadmium stimulates the accumulation of salicylic acid and its putative precursors in maize (Zea mays L.) plants. Physiol Plant $125: 356-364$

Pál M, Kovács V, Vida G, Szalai G, Janda T (2013) Changes induced by powdery mildew in the salicylic acid and polyamine contents and the antioxidant enzyme activities of wheat lines. Eur J Plant Pathol 135:35-47

Pál M, Kovács V, Szalai G, Soós V, Ma X, Liu H, Mei H, Janda T (2014) Salicylic acid and abiotic stress responses in rice. J Agron Crop Sci 200:1-11

Pancheva TV, Popova LP, Uzunova AN (1996) Effects of salicylic acid on growth and photosynthesis in barley plants. J Plant Physiol 149:57-63

Pancheva TV, Popova LP (1998) Effect of salicylic acid on the synthesis of ribulose-1,5bisphosphate carboxylase/oxygenase in barley leaves. J Plant Physiol 152:381-386

Penuelas J, Munné-Bosch S (2005) Isoprenoids: an evolutionary pool for photoprotection, Trends Plant Sci 10:166-169

Poór P, Gémes K, Horváth F, Szepesi Á, Simon ML, Tari I (2011) Salicylic acid treatment via the rooting medium interferes with stomatal response, $\mathrm{CO}_{2}$ fixation rate and 
carbohydrate metabolism in tomato, and decreases harmful effects of subsequent salt stress. Plant Biol 13:105-114

Poór P, Tari I (2012) Regulation of stomatal movement and photosynthetic activity in guard cells of tomato abaxial epidermal peels by salicylic acid. Funct Plant Biol 39:1028-1037 Popova LP, Maslenkova LT, Yordanova RY, Ivanova AP, Krantev AP, Szalai G, Janda T (2009) Exogenous treatment with salicylic acid attenuates cadmium toxicity in pea seedlings. Plant Physiol Biochem 47:224-231

Qiu C, Ji W, Guo Y 82011) Effects of high temperature and strong light on chlorophyll fluorescence, the D1 protein, and Deg1 protease in Satsuma mandarin, and the protective role of salicylic acid. Acta Ecol Sinica 31:3802-3810

Radwan DEM, Soltan DM (2012) The negative effects of clethodim in photosynthesis and gas-exchange status of maize plants are ameliorated by salicylic acid pretreatment. Photosynthetica 50:171-179

Raskin I (1992a) Role of salicylic acid in plants. Annu Rev Plant Physiol Plant Mol Biol 43:439-463

Raskin I (1992b) Salicylate, a new plant hormone. Plant Physiol 99:799-803

Sahu GK, Kar M, Sabat SC 82002) Electron transport activities of isolated thylakoids from wheat plants grown in salicylic acid. Plant Biol 4:321-328

Saruhan N, Saglam A, Kadioglu A (2012) Salicylic acid pretreatment induces drought tolerance and delays leaf rolling by inducing antioxidant systems in maize genotypes. Acta Physiol Plant 34:97-106

Sasheva P, Yordanova R, Janda T, Szalai G, Maslenkova L (2013) Study of primary photosynthetic reactions in winter wheat cultivars after cold hardening and freezing. Effect of salicylic acid. Bulg J Agric Sci 19:45-48 
Shakirova FM (2007) Role of hormonal system in the manisfestation of growth promoting and anti-stress action of salicylic acid. In: Hayat S, Ahmad A (eds) Salicylic acid, A plant hormone. Springer, Dordrecht, Netherlands pp. 69-89

Silverman P, Seskar M, Kanter D, Schweizer P, Métraux JP, Raskin I (1995) Salicylic acid in rice. Biosynthesis, conjugation, and possible role. Plant Physiol 108:633-639

Singh PK, Gautam S (2013) Role of salicylic acid on physiological and biochemical mechanism of salinity stress tolerance in plants. Acta Physiol Plant 35:2345-2353

Spetea C, Hundal T, Lundin B, Heddad M, Adamska I, Andersson B (2004) Multiple evidence for nucleotide metabolism in the chloroplast thylakoid lumen. Proc Nat Acad Sci USA 101:1409-1414

Szalai G, Janda T (2009) Effect of salt stress on the salicylic acid synthesis in young maize (Zea mays L.) plants. J Agron Crop Sci 195:165-171

Szalai G, Horgosi S, Soós V, Majláth I, Balázs E, Janda T (2011) Salicylic acid treatment of pea seeds induces its de novo synthesis. J Plant Physiol 168:213-219

Szalai G, Krantev A, Yordanova R, Popova LP, Janda T (2013) Influence of salicylic acid on phytochelatin synthesis in Zea mays during Cd stress. Turk J Bot 37:708-714

Tirani MM, Nasibi F, Kalantari KM (2013) Interaction of salicylic acid and ethylene and their effects on some physiological and biochemical parameters in canola plants (Brassica napus L.). Photosynthetica 51:411-418

Tóth SZ, Schansker G, Garab G (2013) The physiological roles and metabolism of ascorbate in chloroplasts. Physiol Plant 148:161-175

Uzunova AN, Popova LP (2000) Effect of salicylic acid on leaf anatomy and chloroplast ultrastructure of barley plants. Photosynthetica 38:243-250

Vicent MRS, Plasencia J (2011) Salicylic acid beyond defence: its role in plant growth and development. J Exp Bot 62:3321-3338. 
Vogt T (2010) Phenylpropanoid biosythesis. Mol Plant 3:2-20

Wang LJ, Fan L, Loescher W, Duan W, Liu GJ, Cheng JS, Luo HB, Li SH (2010) Salicylic acid alleviates decreases in photosynthesis under heat stress and accelerates recovery in grapevine leaves. BMC Plant Biol 10:34

War AR, Paulraj MG, War MY, Ignacimuthu S (2011) Role of salicylic acid in induction of plant defense system in chickpea (Cicer arietinum L.). Plant Signal Behav 6:1787-1792

Wildermuth MC, Dewdney J, Wu G, Ausubel FM (2001) Isochorismate synthase in required to synthesize salicylic acid for plant defence. Nature 414:562-565

Wildermuth MC (2006) Variations on a theme: synthesis and modification of plant benzoic acids. Curr Opin Plant Biol 9:288-296

Wu LJ, Zu XF, Wang XT, Sun AG, Zhang J, Wang SX, Chen YH (2013) Comparative proteomic analysis of the effects of salicylic acid and abscisic acid on maize (Zea mays L.) leaves. Plant Mol Biol Rep 31:507-516

Xue LJ, Guo W, Yuan Y, Anino EO, Nyamdari B, Wilson MC, Frost CJ, Chen HY, Babst BA, Harding SA, Tsai CJ (2013) Constitutively elevated salicylic acid levels alter photosynthesis and oxidative state but not growth in transgenic populous. Plant Cell $25: 2714-2730$

Yalpani N, Enyedi AJ, León J, Raskin I (1994) Ultraviolet light and ozone stimulate accumulation of salicylic acid, pathogenesis-related proteins and virus resistance in tobacco. Planta 193:372-376

Yang Y, Qi M, Mei C (2004) Endogenous salicylic acid protects rice plants from oxidative damage caused by aging as well as biotic and abiotic stress. Plant J 40:909-919

Yoshida S, Ito M, Nishida I, Watanabe A (2002) Identification of a novel gene HYS1/CPR5 that has a repressive role in the induction of leaf senescence and pathogen-defence responses in Arabidopsis thaliana. Plant J 29:427-437 
Yu IC, Parker J, Bent AF (1998) Gene-for-gene disease resistance without the hypersensitive response in Arabidopsis dnd1 mutant. Proc Nat Acad Sci USA 95:7819-7824

Zhao HJ, Zhao XJ, Ma PF, Wang YX, Hu WW, Li LH, Zhao YD (2011) Effects of salicylic acid on protein kinase activity and chloroplast D1 protein degradation in wheat leaves subjected to heat and high light stress. Acta Ecol Sinica 31:259-263 


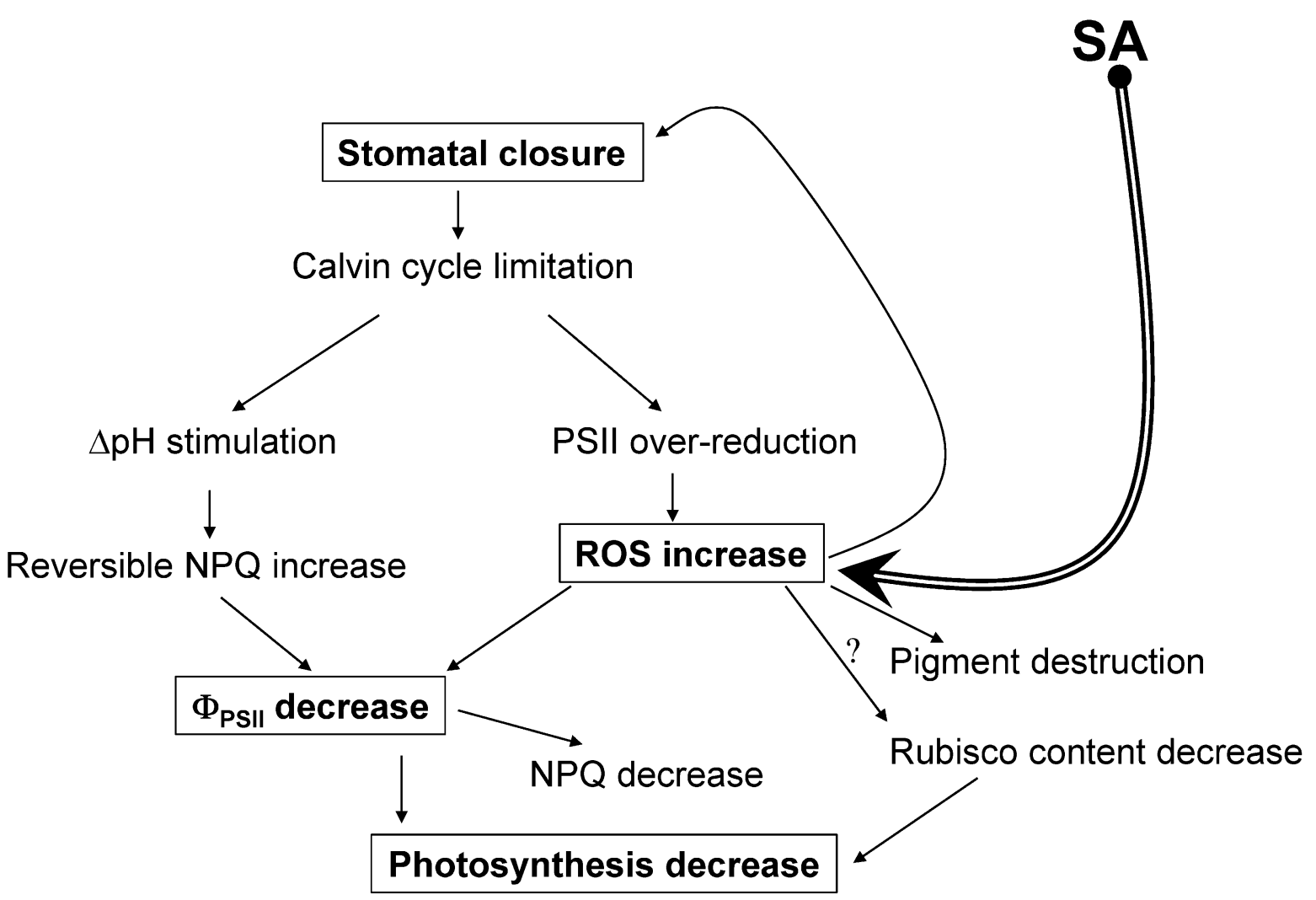

Fig. 1 Schematic representation of the effect of SA on photosynthetic processes. Details in the text. 


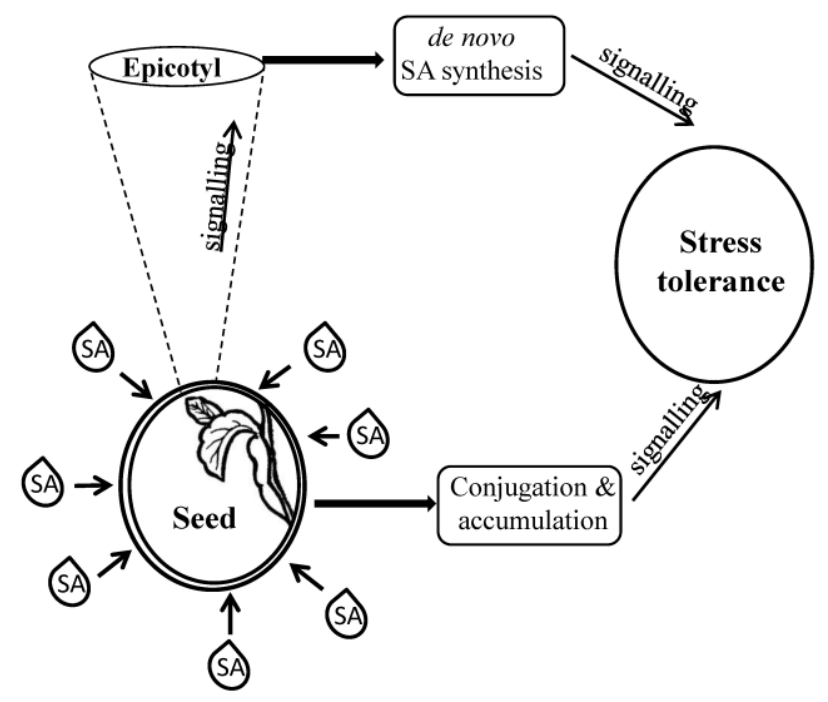

Fig. 2 Exogenous SA may induce de novo SA synthesis in plants (Szalai et al. 2011). 